\title{
Preoccupation with results can be damaging for young coaches
}

\author{
Callum Gowling ${ }^{\mathrm{a}}$ \\ ${ }^{a}$ Liquid Sport Psychology, Great Britain.
}

\section{ABSTRACT}

Sports coaching research can portray an overly simplistic picture of the activity leading to young coaches being underprepared for intra-personal conflicts during coaching careers (Cushion, 2006; Jones, 2009; Potrac et al., 2016). This paper builds on work that shows coaching is emotionally challenging (Thelwell, 2017; Gowling, 2019). Autoethnography illustrates the first authors inner struggles with their perceived effectiveness while trying to prove their worth in the elite junior coaching context. There are four main findings (1) the performance narrative influences young coaches' behaviour; (2) inability to assess one's own effectiveness, without using player results as the sole criteria can have a negative emotional effect on coaches; (3) relational narratives are present in elite junior coaching; (4) provides governing bodies with opportunities to improve the preparation of young coaches for intra-personal challenges related to coaching.
Key words: autoethnography, emotional challenges, young coaches

Received: 10 June 2020

Accepted: 02 September 2020 Corresponding author: Callum Gowling, Great Britain. Email:

callumgowling@btinternet.com

\section{INTRODUCTION}

Researchers argue that coach education does not effectively use the wealth of experience that coaches have to inform the education of new coaches, leaving them underprepared for the complex nature of their role (Cushion, Armour, \& Jones, 2003). New approaches to research, such as autoethnography, lead research away from abstract theorising about coaching, towards more "thickly described, evocative accounts of coaching" practice and culture by using first person accounts of coaching (Geraity, 2014, p. 206). Highly personalised, vulnerable writing followed by theoretical analysis is an effective way for existing coaches to communicate their experiences and inform practice. Autoethnography can inform tennis coach education literature through a vivid insight into emotional challenges that tennis coaches may face.

The purpose of this paper is to provide a first-person account of a coaching relationship with an elite junior tennis player (Junior ITF level) and illustrate how an over reliance on results (performance narrative) influenced my coaching behaviours. The performance narrative is a story of single-minded dedication to sport performance to the exclusion of other areas of self, and relationships (Douglas \& Carless, 2012). Within the plot of the performance narrative, winning, results, and achievements are pre- eminent and link closely to the storyteller's mental well-being, identity, and self-worth. The storyline of the performance narrative is consistent with sport is life and life is sport, and the performance narrative permeates much of junior elite sport participation (Dacyshyn, 1999). The story charts my early experiences as a tennis coach trying to prove that I belonged as a coach to elite junior tennis players. I became fixated on winning as the primary measure of my effectiveness as a coach. With player results suffering and no alternative way of assessing my effectiveness as a coach, I experienced struggles with self-worth, and this affected the coach-athlete relationship through an inability to cope.

\section{METHOD}

The autoethnography is about my personal thoughts and experiences of coaching an elite junior tennis player. I present highly personalised stories as three, sequential, diary entries, illustrating an important series of events during the coaching relationship with Sarah (name changed for anonymity).

Analytic autoethnography uses the self as a means to a theoretical end. Authors communicate their experience through stories and include straightforward interpretation of their stories. The interplay between the story and interpretation leads to theoretical 
insight. This paper tells a story about my emotional struggles during a difficult period in the coaching relationship. After a period of immersion into the data, it became clear that the scaffold and structure holding the stories together was the performance narrative and how I lived that through my coaching identity.

\section{RESULTS}

I present the results as diary extracts from a personal coaching journal to reflect the day's events and how I, as the coach, tried to make sense of my experiences.

Story 1 - Results show me that I am failing.

I'm struggling on court right now. Results haven't been great and the changes I've made to Sarah's game aren't working. I'm concerned whether the changes are the right ones now. Is it me or is it her? I can't help but worry about what her parents think about my coaching? The improvements seem to be harder to come by and the early success we had together seem a distant memory. Her dad wants a catch up and I'm convinced he's gonna get rid of me.

I went to their house while Sarah was at school and mum was at work. The fact no-one else was around made it even more scary. This obviously isn't gonna be good, he's gonna tear a strip off me for all the poor results. We chatted over coffee and politely danced around Sarah and her tennis. After the first coffee, he tops me up and sits back down and there is an awkward silence. Here comes the bullet.

He tells me they are up against it financially and he is thinking of downsizing their house to help pay for the tennis. My brain went into overdrive, thinking about what was coming next. Surely, he is going to tell me now that they are sending her to an academy and investing in 'better coaching'... The words never came. I was not sure if he wanted reassurance that I was the right man for the job or if he wanted me to tell him to stop her tennis. I'm just a tennis coach, am I meant to know how to respond in this situation?

He told me that he really appreciated the work I was doing, and I had a positive effect on her way beyond the tennis court. He wanted me as coach no matter what. I thought, "Appreciate the work I'm doing? She's been losing!"

Story $2-$ My inability to cope.

I picked Sarah up from school and brought her to the centre. I had a lesson beforehand with a different player. I can see Sarah sat down, chatting away without a care in the world. "Where is the warm-up please? You're on in 20 mins and you're not looking too ready". My attention is now not on my current lesson, I'm consumed with frustration because of the lack of discipline. 10 minutes to go, still no movement... "Come on Sarah, show me something!" As I finish my lesson I am consumed with frustration with Sarah. What am I going to say to her? I can't be responsible for her missing school and her not showing discipline. What will her parents think of this? Is this just a jolly? Do something about it!

Sarah walked onto court, oblivious to my mood. I imagined all her rivals and what their warm-ups would be in the same situation.
Early to practice, energetic, dynamic, organised, disciplined... Perfect. I described the scene to Sarah, over exaggerating what I imagined the perfect warm-up to be and then compared it to what I had witnessed from her. She clearly felt that these days out of school were no more than an opportunity to revel in her own selfimportance. Coming out of school just to sit and chat to whoever! Disgrace. All this effort l've gone to, to get you here for your tennis and that's what you do.

I finished my rant and left the court for Sarah to come off court on her own. Her eyes were red, and she made no eye contact. As I left the court the frustration drained from my body, leaving only shame. Who was that speaking? Am I really that person? I sat slumped in the clubroom; deflated, conflicted, disappointed, and reflected on the performance I just put on. I went over all the negative stereotypes of performance coaches I had created over the years when I played. I ticked every box.

Story 3 - Understanding that results aren't everything.

The fallout from that last session has been quite something. I lost the trust and respect of her parents and Sarah is currently working with another coach. Every time I see her it's a reminder of what an idiot I was in that moment and how self-absorbed I had become. Who were my actions really helping? I'm embarrassed.

I still see Sarah, but she clearly feels awkward as we just politely wave nowadays. The awkwardness only makes me feel worse about my behaviour. I saw her today and she was leaving for an ITF. In between my own sessions I felt the need to clear the air with her before she left.

I call her over. As she walks over, I feel sick. Sick at the thought of having to apologise to a teenager for my actions as a supposed mature adult. This feels really humiliating.

I hold nothing back. I'm not so sure any of this is in any coaching manual, "how to apologise to your former players", but it's all I know. Admit your mistakes and treat everyone like you would want to be treated. Sarah is giving me eye contact and does not appear to be gloating - which I'd imagined before embarking on this apology. Once I got most of the painful admissions out of the way, which merely alluded to my own insecurities as a coach, Sarah's facial expressions began to relax, and she looked more like the person I used to coach. The one with an air of mischief around her. "It's all fine Cal. Now can you have a word with my dad and get me back on court with you again coz he's doing my head in".

\section{DISCUSSION}

The stories in this paper contribute to our understanding of coaching in several ways:

First, the stories show the performance narrative strongly influenced my coaching attitude and I had a preoccupation with positive results because I believed this would prove my competence. A period of poor results meant I perceived my coaching negatively and believed others within tennis would judge me as ineffective. The stories contribute to research that says new coaches are over reliant on results as proof of effectiveness (Peet 
et al., 2013; Cassidy et al., 2016) and seeking positive public judgements from others in tennis dominate the daily thoughts and actions of young coaches (Kelchtermans, 2009a).

Second, the stories show how over-reliance on results as a source of confidence can damage self-esteem and self-worth during periods of poor results. The stories show an interplay between the performance narrative and the insecurities of a young tennis coach when trying to develop a socially recognised identity as an effective coach. Poor results and my resultant insecurity produced negative coaching behaviours towards Sarah. The stories contribute to research that highlights coach stress and the potential negative impact on coach-athlete relationships (Thelwell et al., 2017).

Third, the stories show evidence of a young coach learning a new coaching narrative. Relational narratives use care and connectedness to assess effective coaching relationships rather than focussing on results (Douglas \& Carless, 2012). The stories help to show players, coaches, and parents use different criteria to assess coaching relationships. For example, care, connection, and relationship duration are markers of successful coaching relationships, as well as winning. The paper builds on work highlighting that coaches involved in youth sport must use sport effectively to meet the needs of athletes, "rather than simply assuming that pushing them through sports experiences will in some magical way, result in positive outcomes for all of them" (Armour, 2013, p. 20).

Finally, this paper provides governing bodies with opportunities to improve the preparation of young coaches for intra-personal challenges related to coaching. There are potential shared world meanings from my experiences that may reassure new or existing coaches about their own coaching experiences.

\section{CONCLUSION}

My story showed how the performance narrative influenced my early coaching career. My attempt to create a positive reputation as an effective coach caused issues with professional selfunderstanding and relationships with a player. My story shows that $\mathrm{I}$ used the performance narrative to inform my tennis coaching role, and this was influential in my preoccupation tournament results. Interactions with Sarah and her parents contradicted the performance narrative but my rigid adherence to the performance narrative resulted in negative coaching behaviours that contributed to the breakdown of the coaching relationship. My story also shows how reflecting on my coaching helped me to learn and understand a new relational narrative in the elite junior coaching context. I hope the in-depth depictions of my coaching stories provide a catalyst for more autoethnographies into tennis coaching, which lead to more realistic depictions of coaching practice.

\section{REFERENCES}

Armour, K. (2013) Sport Pedagogy: An Introduction for Teaching and Coaching. Abingdon: Routledge, https://doi.org/10.4324/9781315847108

Cushion, C. (2006). Modelling the Complexity of the Coaching Process. International Journal of Sports Coaching, Vol 2 (4), pp $395-400$, https://doi.org/10.1260/174795407783359650

Cushion, C.J., Armour, K.M. and Jones, R.L., (2003). Coach Education and Continuing Professional Development: Experience and Learning to Coach, Quest, 55, 215-230, https://doi.org/10.1080/00336297.2003.10491800

Dacyshyn, A. (1999). When the balance is gone. In J. Coakley and P. Donnelly (Eds.) Inside sports, (pp.214-222). London: Routledge.

Douglas, K. \& Carless, D., (2012). Stories of success: Cultural narratives and personal stories of elite and professional athletes, Reflective Practice: International and Multidisciplinary Perspectives, 13:3, 387-398, https://doi.org/10.1080/14623943.2012.657793

Geraity, B. T. (2014) 'Autoethnography. In L. Nelson, R. Groom, \& P. Potrac, (Eds) Research Methods in Sports Coaching, pp 205 - 216. Abingdon: UK, Routledge.

Gowling, C. (2019). Understanding the pressures of coaching: In sights of young UK coaches working with elite junior tennis players. ITF Coaching \& Sport Science Review, Vol 79, pp 19-21.

Jones, R. L. (2009) Coaching as caring (the smiling gallery): accessing hidden knowledge, Physical Education and Sport Pedagogy, 14:4, 377-390, https://doi.org/10.1080/17408980801976551

Kelchtermans, G. (2009a). Who I am in how I teach the message: Selfunderstanding, vulnerability, and reflection? Teachers and Teaching: Theory and Practice, 15(2):257-272, https://doi.org/10.1080/13540600902875332

Peel, J. Cropley, B. Hanton, S. \& Fleming, S. (2013) Learning through reflection: values, conflicts, and role interactions of a youth sport coach, Reflective Practice, 14:6, 729-742, https://doi.org/10.1080/14623943.2013.815609

Potrac, P. Jones, R. Nelson, L. (2014). Interpretivism. In: Nelson, L. Groom, R.

Potrac, $\mathrm{P}$, (ed.), Research Methods in Sports Coaching, Abingdon: UK, Routledge, https://doi.org/10.4324/9780203797549-4

Thelwell, R. Wagstaff, C. R. D. Chapman, M. T. and Kenttä, G. (2017) Examining coaches' perceptions of how their stress influences the coach-athlete relationship, Journal of Sports Sciences, 35:19, 19281939, https://doi.org/10.1080/02640414.2016.1241422

RECOMMENDED ITF TENNIS ACADEMY CONTENT (CLICK BELOW)

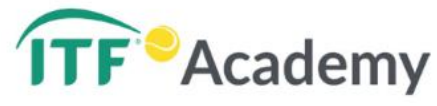

Copyright (c) 2020 Callum Gowling

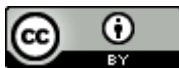

This text is under a Creative Commons BY 4.0 license

You are free to Share - copy and redistribute the material in any medium or format - and Adapt the content - remix, transform, and build upon the material for any purpose, even commercially under the following terms:

Attribution: You must give appropriate credit, provide a link to the license, and indicate if changes were made. You may do so in any reasonable manner, but not in any way that suggests the licensor endorses you or your use. 